\title{
DEVELOPMENT OF HPLC-MS METHOD OF VOGLIBOSE AND QUERCETIN QUANTITATION IN HYPOGLICEMIC ACTION TABLETS
}

\author{
Inna Kovalevska \\ Department Industrial Technology of Drugs \\ National University of Pharmacy \\ 53 Pushkinska str., Kharkiv, Ukraine, 61002 \\ inga.kovalevskaya@gmail.com \\ Olena Ruban \\ Department Industrial Technology of Drugs \\ National University of Pharmacy \\ 53 Pushkinska str., Kharkiv, Ukraine, 61002 \\ ruban_elen@ukr.net \\ Vadim Khanin \\ Ltd. Pharmaceutical company "Zdorovye" \\ 22 Shevchenko str., Kharkiv, Ukraine, 61013 \\ VKhanin@zt.kharkov.ua
}

\begin{abstract}
Aim. The purpose of our study was to develop a method for simultaneous quantitation of voglibose and quercetin in a solid dosage form.

Materials and methods. The objects of the study were voglibose, quercetin, tablets containing voglibose $-0.2 \mathrm{mg}$ and quercetin $100 \mathrm{mg}$. Measurements were carried out by high-performance liquid chromatography (HPLC) according to SPHU, supp. 1, 2.2.29, N, using the following equipment: a mass-selective detector Agilent 6530 Q-TOF was used as the detecting system.

Results. According to the developed method, the quantitative determination of voglibose and quercetin in the tablets of hypoglycaemic action was investigated. The following results were obtained: the content of C $10 \mathrm{H} 21 \mathrm{NO} 7$ (voglibose) in one dosage unit of the test drug was $0.2 \mathrm{mg}$; and the content of $\mathrm{C} 15 \mathrm{H} 10 \mathrm{O} 7$ (quercetin) - $0.105 \mathrm{~g}$, which suggests the validability of the proposed method for quantitation of the active substances in tablets for the prevention and treatment of type II diabetes mellitus.

Conclusions. In the course of the study, a method was developed for determination of voglibose and quercetin in a hypoglycaemic action preparation using high-performance liquid chromatography (HPLC) with a gradient mode of elution. It has been established that the chosen chromatographic conditions allow quantitative determination of the active pharmaceutical ingredients studied in a solid dosage form with a tolerance of $\pm 5 \%$. Validation of the developed methodology has been conducted and its suitability for the simultaneous quantification of quercetin and voglibose in tablets has been demonstrated. The reproducibility of this method has been proved.
\end{abstract}

Keywords: voglibose, quercetin, high-performance liquid chromatography, diabetes mellitus, combination therapy.

\section{Introduction}

Today, diabetes mellitus (DM) is one of the leading medical and social problems that is rapidly gaining momentum: more than 300 million people worldwide suffer this disease [1]. According to the forecasts of the World Health Organization, by 2035 the number of patients with diabetes will increase to 592 million [2]. In Ukraine, according to statistics, the number of patients with diabetes at the beginning of 2018 was 104 thousand, but the real indicator of this pathology incidence is almost 2 times higher [3].

It is proved that monotherapy of type II DM with only one of oral hypoglycaemic drugs has positive results only in the first 5-6 years of the disease, in the future there is a need for the 
combination therapy with drugs from different groups [4]. Therefore, one of the promising directions is the development of combined drugs with various mechanisms of hypoglycemic and prophylactic action in relation to secondary complications with satisfactory biopharmaceutical characteristics [5]. As active pharmaceutical ingredients (APIs), according to the pharmacological studies, it is suggested to use a combination of voglibose and quercetin [6].

Quercetin has powerful antioxidant properties [7]. It is proved that it inhibits processes of not only non-enzyme but also enzymatic lipid peroxidation (LPO) [8], but also protects from oxidation ascorbic acid and adrenaline, whose oxidation products can further activate LPO [9]. It has also been established that quercetin preparations contribute to the reduction of pathological manifestations in type II diabetes, which is accompanied by obesity: hyperglycemia, hyperlipidemia, imbalance in the system of interleukins and nitric oxide in both serum and myocardium [10]. However, its long application is limited due to low solubility [11].

Voglibose belongs to the group of hypoglycaemic agents, which are included in the Unified clinical protocol of primary and secondary (specialized) medical aid in case of type 2 diabetes mellitus, approved by the Ministry of Health of Ukraine dated December 21, 2012, Order No. 1118 [12]. The principle of voglibose action is based on the competitive inhibition of enzymes and a decrease in the rate of glucose release from complex carbohydrates, which leads to a decrease in postprandial hyperglycaemia and a decrease in the level of oxidative stress and inflammatory markers in patients with DM [13]. Voglibose effectively improves glycemic control and helps reduce glycosylated haemoglobin by an average of $2 \%$ without any side effects on weight gain [14]. It was established that the use of voglibose is effective in preventing the occurrence of type II diabetes in people with impaired glucose tolerance [15].

It is known that quantitation of APIs in combined medicines is one of the most difficult tasks of pharmaceutical development.

\section{Aim of research}

Develop a method for simultaneous quantitation of voglibose and quercetin in a solid dosage form.

\section{Materials and methods}

Investigations were carried out in the State scientific-research laboratory of NUPh for medicinal substances quality control in 2018.

The objects of the study were voglibose, quercetin, tablets containing voglibose $-0.2 \mathrm{mg}$ and quercetin $100 \mathrm{mg}$.

Measurements were carried out by high-performance liquid chromatography (HPLC) according to SPHU, supp .1, 2.2.29, N [16], using the following equipment: a mass-selective detector Agilent 6530 Q-TOF was used as the detecting system. This detector was used in conjunction with a liquid chromatograph Agilent 1290 equipped with a diode matrix, a four-channel pump for forming a low-pressure gradient, an automatic sampler and a thermostat of columns. Mass Hunter B04.01 software was used to process the measured results [16]. In addition to the above equipment to conduct research used:

- Electronic laboratory balance ABT 120-5DM

- Starter ST2100 pH meter by Ohaus.

- Measuring glassware of the accuracy class A in the required quantity.

Equipment with metrological certification was used according to the approved standard working method (SWM).

In the following conditions, total ion current chromatograms were obtained for test solutions. Method of quantitation.

The contents of voglibose and quercetin $(\mathrm{X})$, in $\mathrm{mg}$, in a tablet, were calculated by the formula:

$$
\mathrm{x}=\frac{\mathrm{S}_{\mathrm{i}} \times \mathrm{m}_{0} \times 100 \times \mathrm{b} \times \mathrm{P} \times 1000}{\mathrm{~S}_{0} \times \mathrm{m}_{\mathrm{i}} \times 500 \times 100},
$$


where $\mathrm{S}_{\mathrm{i}}$ is the mean value of the peak area of voglibose or quercetin, which is calculated from the chromatograms of the test solution; $\mathrm{S}_{0}$ - average value of peak area of voglibose or quercetin, which is calculated from the chromatograms of the comparison solution; $\mathrm{m}_{0}$ - the weight of the standard sample of voglibose or quercetin CRS, in milligrams; $\mathrm{m}_{\mathrm{i}}$ - weight of drug sample, in milligrams; $\mathrm{P}$ - the content of voglibose or quercetin in the standard CRS sample of the tablet, as a percentage; $\mathrm{b}$ - average weight of the tablet, $\mathrm{mg}$.

The content of $\mathrm{C}_{10} \mathrm{H}_{21} \mathrm{NO}_{7}$ (voglibose) in one dosage unit of the test drug should be from $0.18 \mathrm{mg}$ to $0.22 \mathrm{~g}$.

The content of $\mathrm{C}_{15} \mathrm{H}_{10} \mathrm{O}_{7}$ (quercetin) in a single dosage unit of the test drug should be from 0.9 to $0.11 \mathrm{~g}$.

Measurements were carried out by liquid chromatography. Approximately $600 \mathrm{mg}$ (exact weighting), of the mass of 10 grounded pills placed in a $100 \mathrm{ml}$ volumetric flask, $50 \mathrm{ml}$ of methanol $\mathrm{P}$ was added and placed on an ultrasound bath for 20 minutes. The solution was cooled; the volume of solution was added with methanol P to the label and stirred for 10 minutes. The solution was filtered through a $0.45 \mu \mathrm{m}$ PTFE filter (test solution).

The comparison solution was chromatographed, obtaining from 2 to 6 chromatograms. Injection volume was $80 \mu$ l. Relative standard deviation (RSD) was calculated for areas of voglibose and quercetin peaks on obtained chromatograms.

Obtaining of parallel chromatograms $\left(\mathrm{n}_{0}\right)$ was terminated when the requirements for (RSD) specified in SPHU 2.2.46, N, Table 2.2.46-2 were met.

The solution to be tested and the comparison solution were chromatographed alternately; obtaining the number of parallel chromatograms (n) for each solution is not less than that for checking the suitability of the chromatographic system under the following conditions:

- a column of $250 \times 4.0 \mathrm{~mm}$ which is filled with a octosilicagel-bonded sorbent (L7), a particle size of $5 \mu \mathrm{m}$ XTerra MS C8 (Waters) or a similar one for which the requirements of the section "The suitability of the chromatographic system" are met;

- flow rate $-1 \mathrm{ml} / \mathrm{min}$;

- temperature of the thermostat of the column $-30{ }^{\circ} \mathrm{C}$;

- mobile phase A: $0.005 \mathrm{M}$ solution of ammonium formiate in water $\mathrm{P}$ degassed in any convenient way;

- mobile phase B: 0,005M solution of ammonium formiate in the mixture of acetonitrile $\mathrm{P}$ - water P (90:10) degassed in any convenient way;

- elution mode - isocratic;

- the ratio of the mobile phase A to the mobile phase B should be as 40:60;

- volume of injection $5 \mu \mathrm{l}$;

- detector - mass spectrometer (Agilent 6420 Triple Quad);

- detector settings:

- type of ionization: positive, electric spray (+ESI);

- mode of measurement: the accumulation of ions with a mass of 268 and 302 AU.;

- voltage at fragmentor $50 \mathrm{~V}$;

- temperature of nitrogen $350{ }^{\circ} \mathrm{C}$;

- nitrogen consumption $10 \mathrm{ml} / \mathrm{min}$;

- pressure on the nebuliser 35 PSI;

- voltage at capillary $4 \mathrm{kV}$.

The results of the analysis were considered reliable if the requirements of the test "Checking the suitability of the chromatographic system" were met.

Note. Preparation of the solution for comparison. $5 \mathrm{mg}$ of voglibose and $50 \mathrm{mg}$ of quercetin CRS were placed in a $500 \mathrm{ml}$ volumetric flask, $400 \mathrm{ml}$ of methanol P were added and placed on an ultrasound bath until complete dissolution. The solution was cooled, the volume of solution was added with methanol $\mathrm{P}$ to the mark and stirred. The solution was used freshly prepared.

Checking the suitability of the chromatographic system.

The chromatographic system was considered suitable if the following conditions were met: 
- the efficiency of the chromatographic column, calculated from the peak of voglibose and quercetin on the chromatogram of the comparison solution, should be at least 1000 theoretical plates (SPHU);

- the peak asymmetry coefficient, calculated for the peak of voglibose and quercetin on the chromatogram of the comparison solution, should be no more than 2.0 (SPHU).

\section{Research results}

The uncertainty of voglibose and quercetin content in one tablet should not exceed $\pm 5 \%$, which allows calculating the maximum uncertainty of the method of quantitation $\Delta \mathrm{A} s=1.6 \%$ [17]. Based on these requirements, the validation of the developed technique has been carried out and its suitability for simultaneous quantitation of both voglibose and quercetin in medicinal form was proved. Before carrying out of the basic validation tests, the presence of documents proving the suitability of the used equipment, raw materials and reagents was controlled. Validation of the methodology was carried out in accordance with the requirements of the State Pharmacopoeia of Ukraine [14].

In the above conditions, the chromatograms of the test solution and the comparison solution were obtained (Fig. 1, 2).
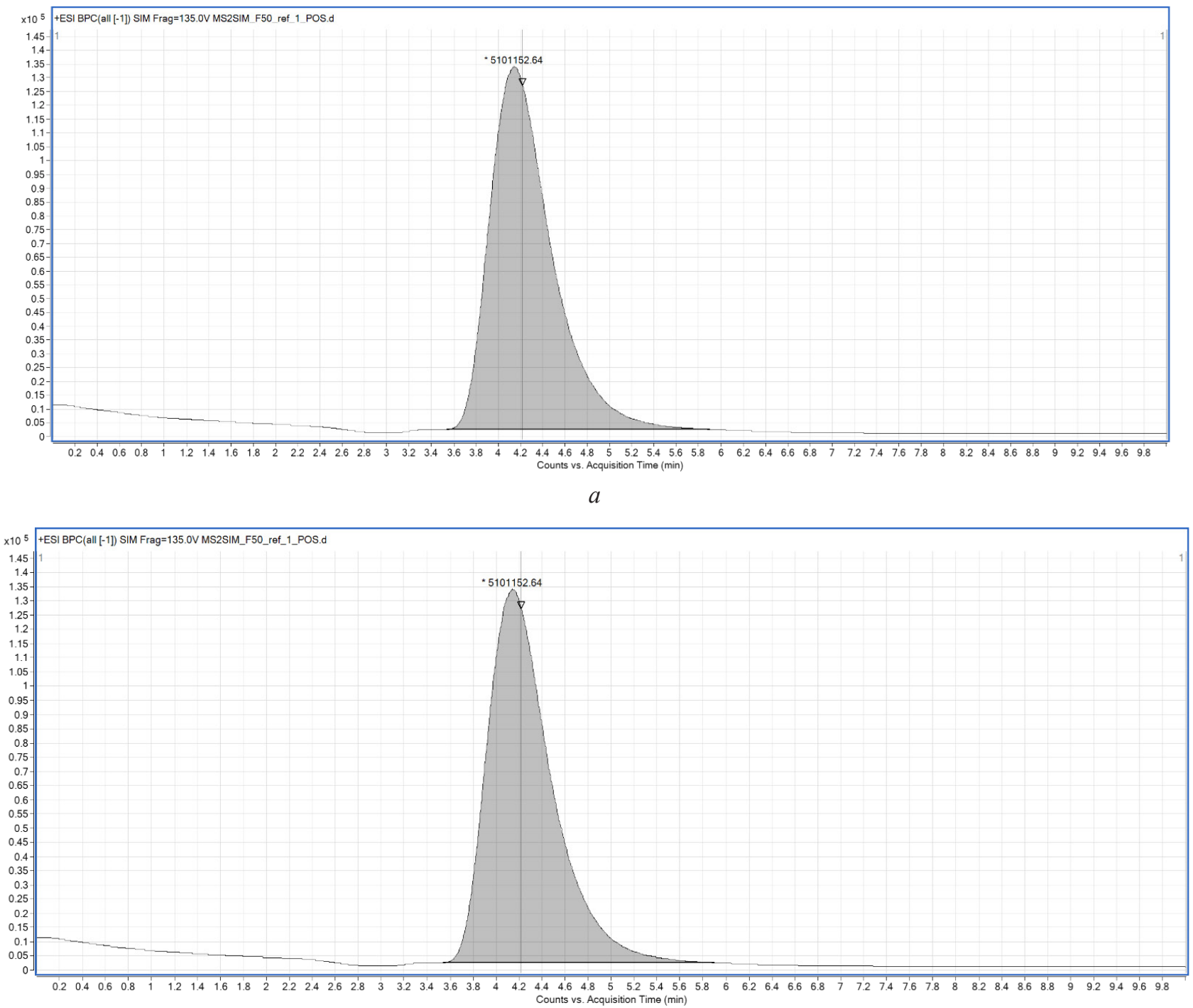

$b$

Fig. 1. Voglibose chromatogram: $a$ - the comparison solution; $b$ - the test solution 
Since the method of high-performance liquid chromatography is specific, to prove it is enough to meet all the requirements for the criteria for linearity, repeatability, precision, accuracy and intermediate precision.

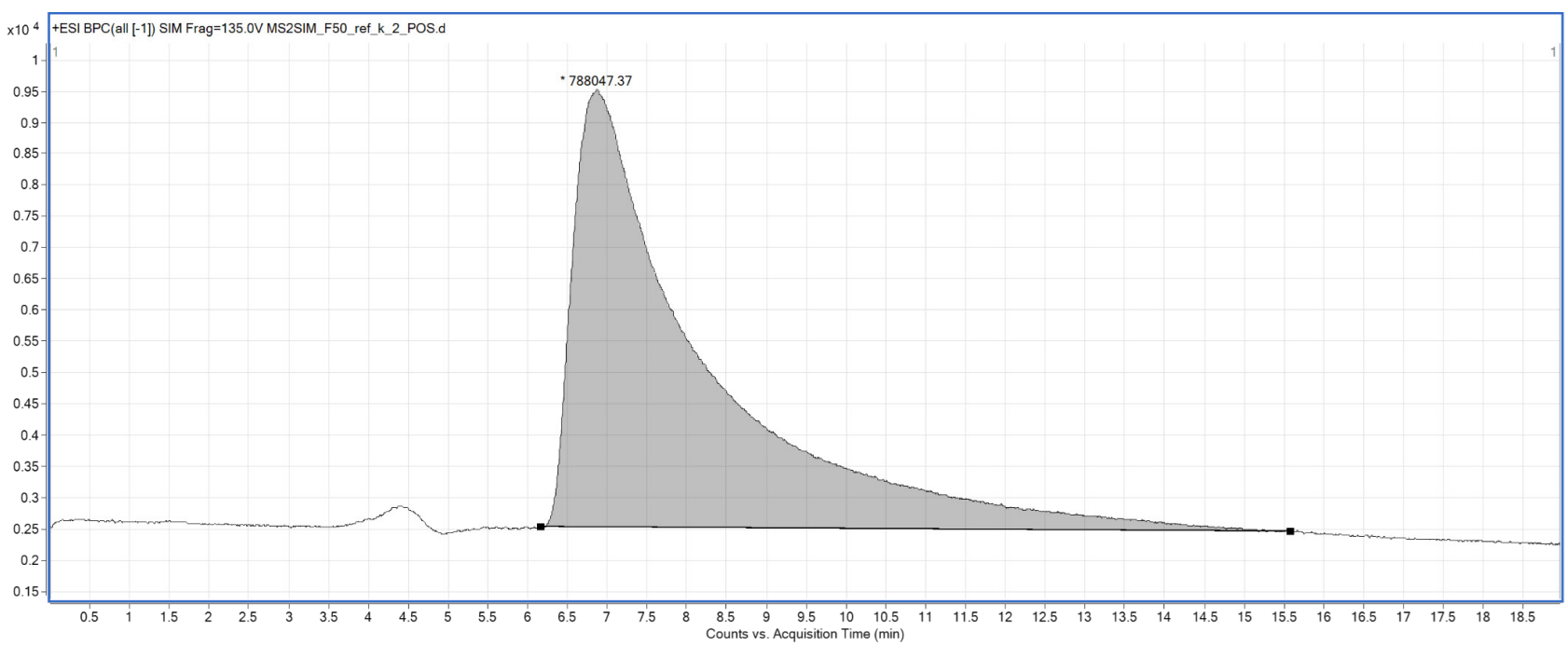

$a$

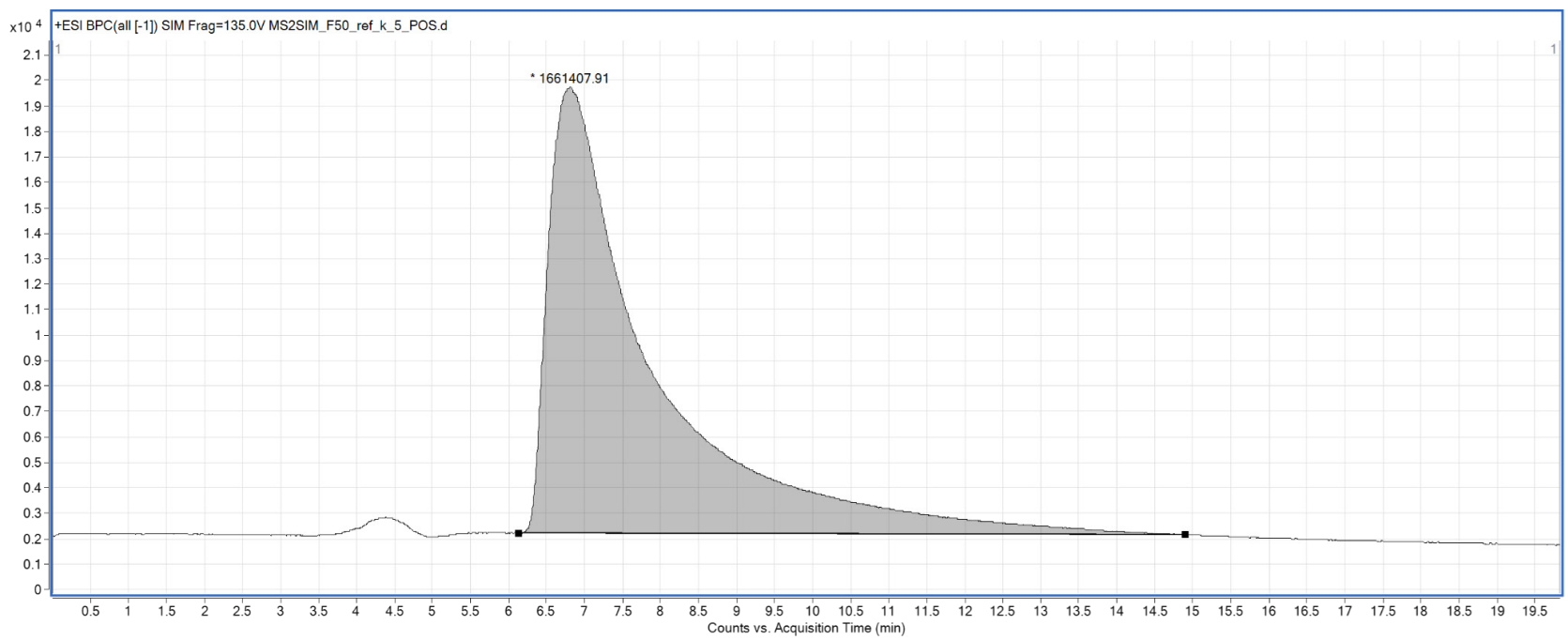

$b$

Fig. 2. Chromatogram of quercetin: $a$-the comparison solution; $b$-the test solution

The linearity evaluation was carried out over the entire range of application of the methodology by the standard method. The study of the nature of the optical density dependence on the concentration was carried out using 9 model solutions for analysis with concentrations: 80, 85, 90, $95,100,105,110,115$ and $120 \%$. The results of the linear dependence of the peak area on the concentration of voglibose and quercetin are shown in Fig. 3, 4, respectively. Characteristics of linear dependence for voglibose and quercetin are presented in Table 1, 2.

In both cases, the linearity requirements are met.

For measuring and calculating the metrological assessment of the repeatability and accuracy of the methodology, three values of peak areas for the comparison solution and 27 values of peak areas for model solutions were obtained. Calculated actual value $\left(\mathrm{Xi}_{\text {fact }}\right)$, the ratio of average values of peak areas for each of the 27 solutions to the mean peak area of reference solution by getting the value of $\mathrm{X}_{\mathrm{i}}=\left(\mathrm{C}_{\mathrm{i}} / \mathrm{C}_{\mathrm{St}} \times 100 \%, \mathrm{Yi}=\left(\mathrm{Si} / \mathrm{S}_{\mathrm{st}}\right) \times 100 \%\right.$, as well as the value of $\mathrm{Z}_{\mathrm{i}}=\left(\mathrm{Y}_{\mathrm{i}} / \mathrm{X}_{\mathrm{i}}\right) \times 100 \%$, which is 
the ratio of found concentration over the introduced in percents. The results of calculations for the investigated APIs are shown in Table 3, 4.

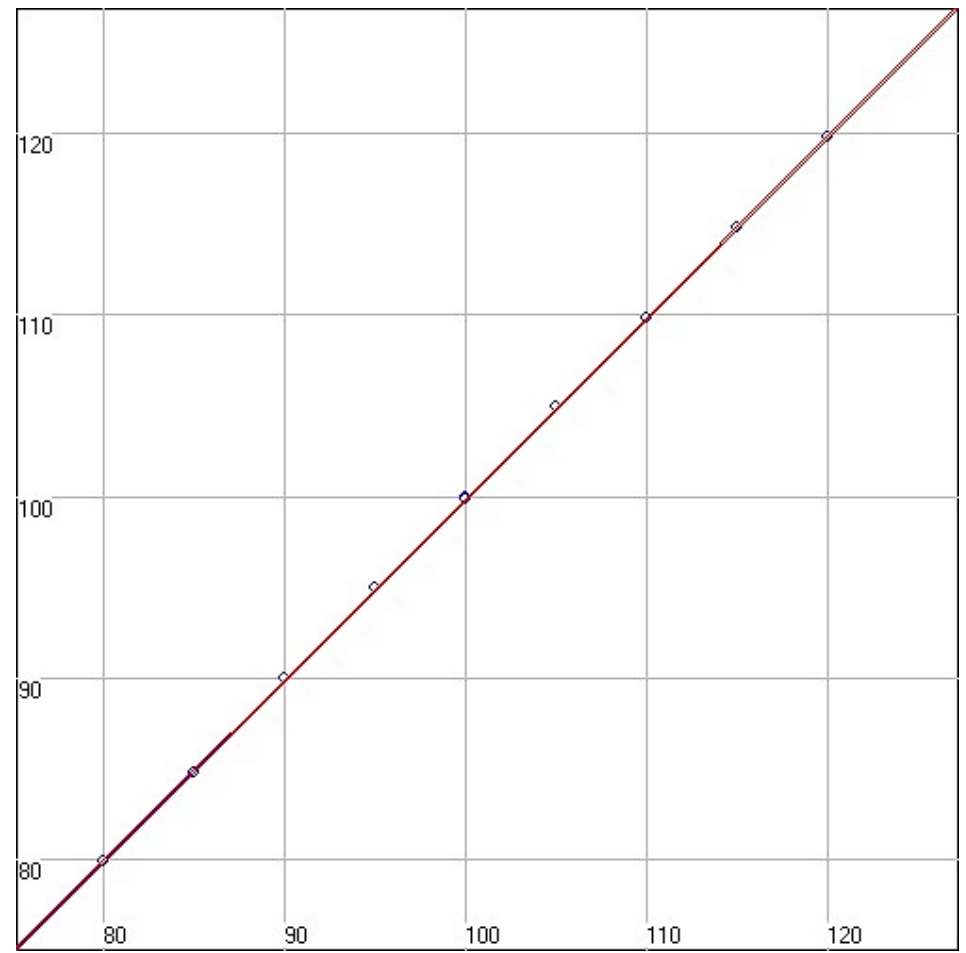

Fig. 3. Linear dependence of the peak area on the concentration of voglibose in normalized coordinates

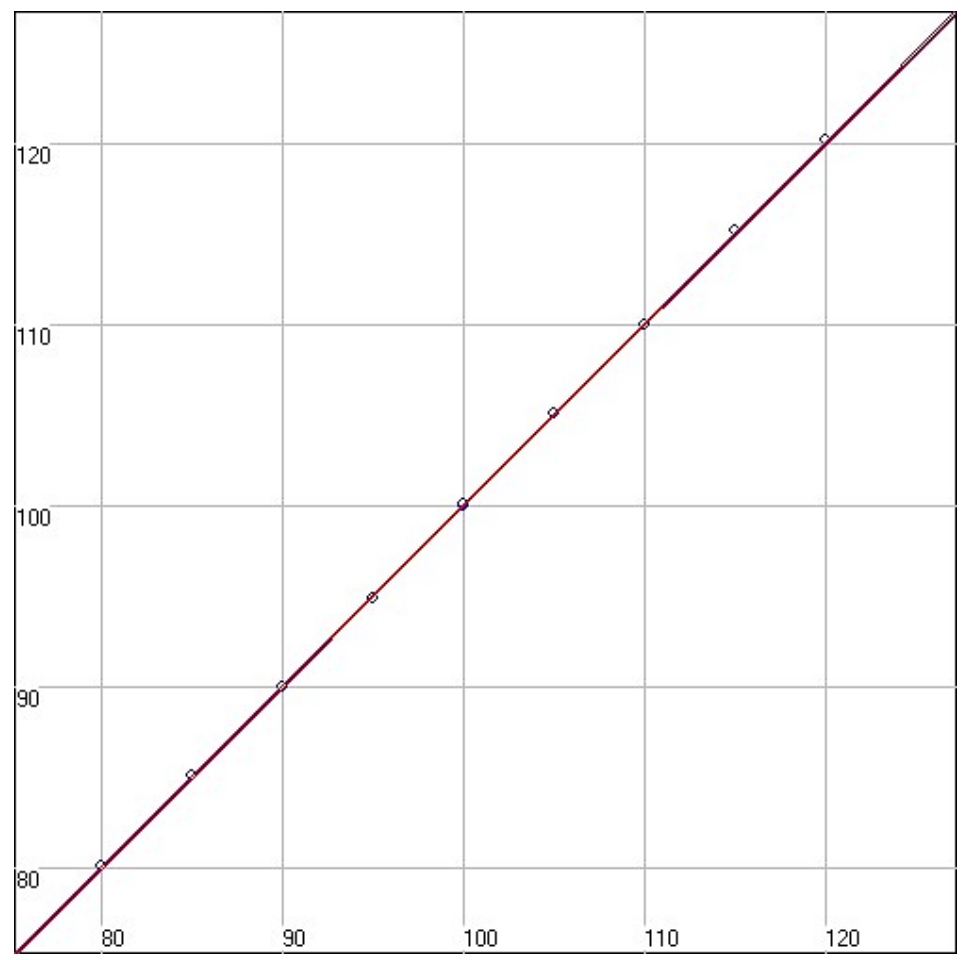

Fig. 4. Linear dependence of peak area on the concentration of quercetin in normalized coordinates 
Table 1

Characteristics of linear dependence for voglibose

\begin{tabular}{|c|c|c|c|c|}
\hline Parameters & Value & Requirement 1 & Requirement 2 & Conclusion \\
\hline $\mathrm{b}$ & 0.99864235 & & & \\
\hline $\mathrm{Sb}$ & 0.0020435845 & & & \\
\hline $\mathrm{a}$ & $|0.045855281|$ & $<=|0.38284396|$ & $<=|2.528|$ & $\begin{array}{l}\text { the first criterion are } \\
\text { respected }\end{array}$ \\
\hline $\mathrm{Sa}$ & 0.20588543 & & & \\
\hline $\mathrm{RSD}_{0}$ & 0.079147686 & & & \\
\hline $\mathrm{RSD}_{0} / \mathrm{b}$ & $|0.079255287|$ & $<=|0.86044636|$ & & are maintained \\
\hline $\mathrm{RSD}_{\mathrm{y}}$ & 12.909944 & & & \\
\hline $\mathrm{r}$ & |0.99998121| & $>|0.99777642|$ & & are maintained \\
\hline
\end{tabular}

Note: Student $(95,1,8)=1.8595, r$ - the relative retention of the component, $R S D(\%)$ - relative standard deviation, $b$ - the angle of inclination, $a$-free member straight, $S$ - the tangent of the angle of the calibration curve

Table 2

Characteristics of linear dependence for quercetin

\begin{tabular}{|c|c|c|c|c|}
\hline Parameters & Value & Requirement 1 & Requirement 2 & Conclusion \\
\hline $\mathrm{b}$ & 1.0026694 & & & \\
\hline $\mathrm{Sb}$ & 0.0024905942 & & & \\
\hline $\mathrm{a}$ & $|-0.19287495|$ & $<=|0.4665865|$ & $<=|2.528|$ & $\begin{array}{l}\text { the first criterion are } \\
\text { respected }\end{array}$ \\
\hline $\mathrm{Sa}$ & 0.25092041 & & & \\
\hline $\mathrm{RSD}_{0}$ & 0.096460298 & & & \\
\hline $\mathrm{RSD}_{0} / \mathrm{b}$ & $|0.096203492|$ & $<=|0.86044636|$ & & are maintained \\
\hline $\mathrm{RSD}_{\mathrm{y}}$ & 12.909944 & & & \\
\hline $\mathrm{r}$ & |0.99997209 & $>|0.99777642|$ & & are maintained \\
\hline
\end{tabular}

Note: Student $(95,1,8)=1.8595$.

Table 3

Results of analysis of model solutions of voglibose and their statistical processing

\begin{tabular}{ccccccc}
\hline Solutions & Name & Medium $\mathbf{S}_{\mathbf{i}}$ & $\mathbf{C}_{\mathbf{i}}$ & $\mathbf{S}_{\mathrm{ir}}$ & $\mathbf{C}_{\mathrm{ir}}$ & $\mathbf{d}_{\mathbf{i}}$ \\
\hline 1 & RS & 16578534 & 100 & 100 & 100 & 100 \\
2 & M1 & 13243263 & 80 & 79.881988 & 80 & 99.852485 \\
3 & M2 & 14062795 & 85 & 84.825323 & 85 & 99.794498 \\
4 & M3 & 14920395 & 90 & 89.998274 & 90 & 99.998083 \\
5 & M4 & 15750280 & 95 & 95.004055 & 95 & 100.00427 \\
6 & M5 & 16556170 & 100 & 99.8651 & 100 & 99.8651 \\
7 & M6 & 17405127 & 105 & 104.98592 & 105 & 99.986591 \\
8 & M7 & 18210479 & 110 & 109.84372 & 110 & 99.857927 \\
10 & M8 & 19042474 & 115 & 114.86223 & 115 & 99.880198
\end{tabular}


Table 4

Results of analysis of model solutions of quercetin and their statistical processing

\begin{tabular}{ccccccc}
\hline Solutions & Name & Medium $\mathbf{S}_{\mathbf{i}}$ & $\mathbf{C}_{\mathbf{i}}$ & $\mathbf{S}_{\mathbf{i r}}$ & $\mathbf{C}_{\mathbf{i r}}$ & $\mathbf{d}_{\mathbf{i}}$ \\
\hline 1 & RS & 1524874 & 100 & 100 & 100 & 100 \\
2 & M1 & 1221600.5 & 80 & 80.11157 & 80 & 100.13946 \\
3 & M2 & 1297765.5 & 85 & 85.106409 & 85 & 100.12519 \\
4 & M3 & 1372048.5 & 90 & 89.977828 & 90 & 99.975364 \\
5 & M4 & 1447766.5 & 95 & 94.943353 & 95 & 99.940371 \\
6 & M5 & 1526486.5 & 100 & 100.10575 & 100 & 100.10575 \\
7 & M6 & 1603155 & 105 & 105.1336 & 105 & 100.12724 \\
8 & M7 & 1676719.5 & 110 & 109.9579 & 110 & 99.961732 \\
9 & M8 & 1756670.5 & 115 & 115.20103 & 115 & 100.17481
\end{tabular}

\section{Discussion of the research results}

The obtained results of voglibose and quercetin quantitation in the preparation developed according to the given method testify to its reproducibility.

Validation of voglibose and quercetin quantitation method was carried out according to individual validation characteristics: specificity, linearity, repeatability, precision, accuracy and intermediate precision.

In order to estimate the sampling error of the model solutions and the comparison solution, the theoretical values of the uncertainty of the analytical operation were calculated, which was $\Delta \mathrm{sp}=0.5 \%$.

During the validation it was proved that sample preparation slightly affects the result of the quantitative determination, so it was not analysed [18].

The obtained results were statistically processed by the method of least squares in accordance with the requirements of the SPHU.

Requirements for linear dependency parameters are met throughout the range of application of the technique (80-120\%).

For the estimation of intermediate precision, a relative confidence interval for 5 parallel determinations of the substances' quantitative content was used, which should be less than the maximum uncertainty of the results of the analysis: $\Delta \mathrm{z} \leq 1.6 \%$. The tests were performed using one series of the drug with different analysts on a single chromatograph on different days using different measuring glassware.

Intermediate precision was confirmed by the fact that the value of the relative confidence interval for five parallel determinations of one series of the drug meets the eligibility criterion.

According to the developed method, the quantitative determination of voglibose and quercetin in the tablets of hypoglycaemic action was investigated [19]. The following results were obtained: the content of $\mathrm{C}_{10} \mathrm{H}_{21} \mathrm{NO}_{7}$ (voglibose) in one dosage unit of the test drug was $0.2 \mathrm{mg}$; and the content of $\mathrm{C}_{15} \mathrm{H}_{10} \mathrm{O}_{7}$ (quercetin) $-0.105 \mathrm{~g}$, which suggests the validity of the proposed method for quantitation of the active substances in tablets for the prevention and treatment of type II diabetes mellitus [20].

\section{Conclusions}

1. In the course of the study, a method was developed for determination of voglibose and quercetin in a hypoglycaemic action preparation using high-performance liquid chromatography (HPLC) with a gradient mode of elution

2. It has been established that the chromatographic conditions chosen allow quantitative determination of the active pharmaceutical ingredients studied in a solid dosage form with a tolerance of $\pm 5 \%$. 
3. Validation of the developed methodology has been conducted and its suitability for the simultaneous quantification of quercetin and voglibose in tablets has been demonstrated. The reproducibility of this method has been proved.

\section{References}

[1] Whiting, D. R., Guariguata, L., Weil, C., Shaw, J. (2011). IDF Diabetes Atlas: Global estimates of the prevalence of diabetes for 2011 and 2030. Diabetes Research and Clinical Practice, 94 (3), 311-321. doi: http://doi.org/10.1016/j.diabres.2011.10.029

[2] Hollander, P. (2007). Anti-Diabetes and Anti-Obesity Medications: Effects on Weight in People With Diabetes. Diabetes Spectrum, 20 (3), 159-165. doi: http://doi.org/10.2337/diaspect.20.3.159

[3] Chaudhury, A., Duvoor, C., Reddy Dendi, V. S., Kraleti, S., Chada, A., Ravilla, R. et. al. (2017). Clinical Review of Antidiabetic Drugs: Implications for Type 2 Diabetes Mellitus Management. Frontiers in Endocrinology, 8. doi: http://doi.org/10.3389/fendo.2017.00006

[4] Neborachko, M., Pkhakadze, A., Vlasenko, I. (2018). Current trends of digital solutions for diabetes management. Diabetes \& Metabolic Syndrome: Clinical Research \& Reviews, 12 (4). doi: http:// doi.org/10.1016/j.dsx.2018.07.014

[5] Germanyuk, T. A., Ivko, T. I. (2014). Rational choice of monotherapy for the treatment of type 2 diabetes mellitus based on the pharmacoeconomical analysis. ScienceRise, (5 (4 (5)), 69-72. doi: http:// doi.org/10.15587/2313-8416.2014.32109

[6] Nyenwe, E. A., Jerkins, T. W., Umpierrez, G. E., Kitabchi, A. E. (2011). Management of type 2 diabetes: evolving strategies for the treatment of patients with type 2 diabetes. Metabolism, 60 (1), 1-23. doi: http://doi.org/10.1016/j.metabol.2010.09.010

[7] Singh Baghel, S., Shrivastava, N., Singh Baghel, R., Agrawal, P., Rajput, S. (2012). A review of quercetin: antioxidant and anticancer properties. World journal of pharmacy and pharmaceutical sciences, 1 (1), 146-160.

[8] Butler, M. S., Robertson, A. A. B., Cooper, M. A. (2014). Natural product and natural product derived drugs in clinical trials. Natural Product Reports, 31 (11), 1612-1661. doi: http://doi.org/10.1039/c4np00064a

[9] Boots, A. W., Haenen, G. R. M. M., Bast, A. (2008). Health effects of quercetin: From antioxidant to nutraceutical. European Journal of Pharmacology, 585 (2-3), 325-337. doi: http://doi.org/10.1016/ j.ejphar.2008.03.008

[10] Chikitkina, O. M., Kononenko, N. M. (2015). Antioxidant properties of a new combined agent glikverin in terms of chemically induced absolute insulin deficiency. Topical issues of new drugs development. Kharkiv: NUPh, 646.

[11] Kovalevska, I., Ruban, O. (2018). Development of the methodological approach of obtaining preparations based on solid dispersions. ScienceRise: Pharmaceutical Science, 4 (14), 4-8. doi: http://doi.org/ 10.15587/2519-4852.2018.140756

[12] Dabhi, A. S., Bhatt, N. R., Shah, M. J. (2013). Voglibose: an alpha glucosidase inhibitor. Journal of Clinical and Diagnostic Research, 7 (12), 3023-3027. doi: http://doi.org/10.7860/jcdr/2013/6373.3838

[13] Kovalevska, I. V., Ruban, O. A. (2018). Modern direction of increasing bioavailability of drugs. Young scientists' view of modern science. Morrisville: Lulu Press, 89-94.

[14] Kaku, K. (2014). Efficacy of voglibose in type 2 diabetes. Expert Opinion on Pharmacotherapy, 15 (8), 1181-1190. doi: http://doi.org/10.1517/14656566.2014.918956

[15] Dabhi, A. S., Bhatt, N. R., Shah, M. J. (2013). Voglibose: an alpha glucosidase inhibitor. Journal of Clinical and Diagnostic Research, 7 (12), 3023-3027.

[16] State Pharmacopoeia of Ukraine. Vol. 2 (2014). Kharkiv: State Enterprise \&quot; Ukrainian Scientific Pharmacopoeial Center for Quality of Medicinal Products\&quot, 1125.

[17] Shabir, G. A. (2003). Validation of high-performance liquid chromatography methods for pharmaceutical analysis: Understanding the differences and similarities between validation requirements of the US Food and Drug Administration, the US Pharmacopeia and the International Conference on Harmonization. Journal of Chromatography A, 987 (1-2), 57-66. doi: http://doi.org/10.1016/s0021-9673(02)01536-4

[18] Batrawi, N., Wahdan, S., Abualhasan, M. (2017). Analytical Method Validation of High-Performance Liquid Chromatography and Stability-Indicating Study of Medroxyprogesterone Acetate Intravaginal Sponges. Analytical Chemistry Insights, 12. doi: http://doi.org/10.1177/1177390117690152

[19] Chikitkina, O. M., Kononenko, N. M., Kovalevsky, I. V. (2015). Experimental substantiation of the dose of voligibose in the new antidiabetic agent gliverine. Ukrainian biopharmaceutical journal, 2, 38-43.

[20] Kovalevskaya, I. V., Kononenko, N. N., Chikitkina, O. M., Chikitkina, V. V. (2014). Experimental substantiation of dose selection and carrier for quercetin substance in the new antidiabetic agent Glikverin. Pharmacology and Drug Toxicology, 3, 57-63. 